\title{
PROBLEMS OF LEGAL REGULATION OF THE ACTIVITY OF THE HEALERS IN UZBEKISTAN
}

Khonnazarov Ruzimuhammad Abdukakhorovich

$\mathrm{PhD}$, Scientific research fellow in Academy of Public Administration

under the President of the Republic of Uzbekistan

$\checkmark$ Crossref

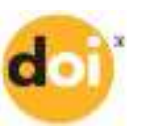

http://dx.doi.org/10.26739/2433-202x

Issue DOI http:/ / dx.doi.org/10.26739/2433-202x-2017-12-12

Article DOI http://dx.doi.org/10.26739/2433-202x-2017-12-12-10

\section{Abstract}

The article deals with the issues of legal regulation, licensing and effective state management of folk medicine.

Key words: health, folk medicine, healer, activity of healers, legal regulation, licensing, management.

Medical activity in Uzbekistan is carried out by the Constitution of the Republic of Uzbekistan. In Article 40 of the Constitution of Uzbekistan written that, everyone has the right to take a qualified health care [1].This Constitutional norm has been developed in accordance with the requirements of a number of International health conventions. Ones of them are Conventions on human rights and freedoms [2]. In general, citizens' rights on health care are protected at two levels: national and international levels. Today, Uzbekistan has established a national legal base for protecting of population. For example, the laws "On state sanitary control", "On public health care", "On drugs and pharmaceutical activities", "On donation of blood and its compounds", "On prevention of iodine deficiency diseases" and "On prevention of micronutrient deficiency" [3].

Currently, national legislation is developing and improving not only in Uzbekistan, but also in many other countries. However, there are many problems to be solved.

Despite the development of modern medicine in Uzbekistan and the improvement of national legislation in this field, the number of people's Khonnazarov Ruzimuhammad Abdukakhorovich 
appeals to folk medicine (healers) is growing day by day. The cause of illness is believed to result from the purposeful intervention of an agent such as a supernatural being; for example, a deity or a god; a nonhuman being, such as a ghost, ancestor, or evil spirit; or a human being such as a witch or sorcerer. The general belief is that the sick person is a victim, the object of aggression or punishment directed specifically against him for reasons that concern him alone. The reasons for this are different and we consider to analyses some of them [ ${ }^{4}$. For example, the limited access of official medicine to free medical care for patients, the high cost of services in public and private health facilities and cost of services are higher than the population's income, corruption and low professionalism of medical staff, drugs are several times more expensive than the population's income, the drugs contains from chemical instructions and the desire of the population to treat naturally occurring natural remedies, the impossibility of modern medicine for the treatment of chronic diseases, in particular, modern doctors recommend that the patient "We did all that we can, go to another doctor", even in result of saying by doctors that patient's life come over, the condition of the patient becomes worse and then patients addresses the healers who ensure patients to live more and says "You will live a long time, the doctor has misinformed, and I guarantee you will live for at least thirty years".

According to the researches of the National academy of folk medicine of Uzbekistan, about two from thirds of the population of our country refer to folk medicine (a healer) at least once a year.

Another interesting aspect is that $95 \%$ of specialists in the field of folk medicine do not have a diploma of medical education. When studying the composition of citizens engaged in folk medicine, it became clear that in this activity are engaged the specialists from different ages and diverse fields. For example, analyzing by age aspect it was known that people from the age of 15 years until people under the age of 100 have been working in folk medicine.

We found the diverse in studying the professional aspect of people who works in folk medicine. For example, citizens with a diploma of higher or secondary medical education are 5\%, the rest are veterinarians with higher or secondary education, internal affairs, agricultural workers, citizens without general or secondary special education, men and women, etc. In general, we can meet representatives of any sphere.

In this case, have a question. Can anybody to be a healer regardless of age or profession in Uzbekistan? Let us put the question in otherwise, will the folk medicine in our country be a good one? 
We have to analyze our national legislation for accurately and legally answer for this question. The analysis of legislative acts in the field of healthcare of the Republic of Uzbekistan. At present, there is no word of folk medicine or healer in any normative document. The folk medicine is not included even in the national encyclopedia of the Republic of Uzbekistan. Nobody can answer the question of folk medicine now. It would be recognize that in Article 44 of the Law of the Republic of Uzbekistan "On the protection of the health of the citizens," only one word "Healer" was preserved. This norm is called "Oath of the Doctors of the Republic of Uzbekistan", "Those who receive a diploma of doctor of medicine are sworn in as follows:... I swear to continue the glorious traditions of such eminent healers as Bugrot, Abu Ali ibn Sina".

At the same time, our national legislation does not provide legal definition of folk medicine. This activity field was not legally evaluated. As we can see that any law does not prohibit this sphere and their income is not taxed, any people can deals with this sphere.

For many years, this issue has been neglecting by the public authorities responsible for the coordination of health care. We found it necessary in our research to clarify a historical normative document, in order to clarify why the folk medicine in such condition.

In the Soviet era, the healers accused as "Healerism" and who were deals with this activity, they were persecuted and expelled to faraway places. Their property was confiscated. Official measures were taken.

On October 31, 1926, by the decision of the Central Executive Committee of the Soviet Socialist Republic № 99 (CEC of the Soviets) and the Soviet People's Commissariat of the USSR [5], as well as by some territorial jurisdictions, the activities of healers were forbidden and their property was confiscated [ ${ }^{6}$. Since then, folk medicine has been out of the law, and the activities of healers have become unofficial.

As a result of independence, along with all the restored and renewed values, we have been able to explore the centuries-old experience and traditions of Uzbek folk medicine and implement them in our present life. The national health system and its legal bases were created. People were allowed to work in folk medicine individually. Later, the legal basis of folk medicine was excluded from the law [7]. However, the norm prohibiting the work in folk medicine was not included in the legislation.

Thus, the folk medicine has become a kind of activity prohibited and not banned by law in Uzbekistan. Timely aware of this situation, some entrepreneurs have used vacuum in the law, registering healers engaged in Khonnazarov Ruzimuhammad Abdukakhorovich 
folk medicine by organizing legal entities, carrying out certification and even licenses in the form of permits and coordinating folk medicine. They take great benefit from this activity. Income is not taxable. Law enforcement agencies are also considering the "licenses" provided by them as an official document.

What should be done to solve the above issues?

The following illustrates the need to adopt a separate law aimed at solving these issues and regulating the activities of healers. In this regard, we tried to develop the concept of the project of the law "On folk medicine".

\section{Fundamentals of development of the project of the law}

On the basis ofthe Decree of the President of the Republic of Uzbekistan DP-3358 "On improvement of the system of the state bodies of the Republic of Uzbekistan" from December 9, 2003,the Decree of the President of the Republic of Uzbekistan DP-2171 "On support of Ibn Sino international fund" from January 6, 1999, the Resolution of the Cabinet of Ministers of the Republic of Uzbekistan №36 "About organization and activity of Ibn Sino international fund" from January 25, 1999, the Strategy of the World Health Organization (WHO) in the field of folk medicine - 2014-2023, IV-priority of the Social Sector of the Strategy for Action on the Development in the Five Priorities of Development of the Republic of Uzbekistan for 2017-2021, the Resolution of the Cabinet of Ministers of the Republic of Uzbekistan № 227 "On Approval of the Regulation on the preparation and acceptance the programs for the development of draft law Legislative Chamber of the Oliy Majlis of the Republic of Uzbekistan as well as monitoring their implementation" from August 5, 2011, the project of the law of the Republic of Uzbekistan "On folk medicine" is developed.

\section{The necessity of development the project of the law}

Along with reforms in the healthcare system of the country, wideranging renewal and stages of development, along with targeted programs, the formation of a legitimate system for the development the heritage of our ancestors' folk medicine, strengthening its legal capacity is an urgent issue.

Oneof the most urgent tasks is to determine the legal status of folk medicine because healers should regulated by law because they are directly related to the lives and health of citizens.

There is not any normative documents with the specialty "Healer", which registered in the legislation of the Republic of Uzbekistan, the Ministry of Health, the Ministry of Employment and Labor, and the Ministry of Justice. That is why at present the income of citizens engaged in the activity of healer is not taxed. 
According to the State Statistics Committee, there are 2516 folk medicine services organizations in the republic. Nevertheless, in fact, it is no secret that this activity is several times higher among those who are engaged without official registration. There is no single register of folk medicine in the country. Some commercial and non-profit legal entities register citizens as "Healers" and issue permits for them to engage in folk medicine activities. In fact, in the charters of such organizations, they do not have the right to give permission for the activities of folk medicine and coordinate their activities. Because the state registration bodies of legal entities do not allow the activity of folk medicine to be engaged as it is not regulated by law. However, the commercial and non-profit legal entities use the term "folk medicine" in the name of a legal entity and use the term "Center of Folk Medicine" and "Academy of Folk medicine". In their chapters, do not define the right to work in folk medicine or to coordinate the activities of folk medicine.

Despite the fact that there are many healers in the field of folk medicine and the size of their services, there is no legal basis for the regulation of folk medicine in our country. This creates conditions for non-professional people to engage in folk medicine activities and do not pay taxes to the budget, concealing their real earnings from this activity.

Due to the lack of control and coordination of activities of folk medicine by state authorities, there have high risks of activities of healers' services and their relationships with the population. The healer's services in the field of folk medicine and an abundance of prices for these services create the basis for various types of abuse in this area and neglect the legitimate rights and interests of the healer's services. This is confirmed by the Supreme Court's consideration of 1,529 cases of consumer rights abuses committed by representatives of folk medicine services in 2010-2017. It should be noted that in practice, in most cases, victims do not apply to courts because of the lack of formal agreements between "healers" and users of their services.

In turn, the lack of a legal framework has created inconveniences and various problems for respected physicians in the field of traditional medicine, as well as for organizations operating under the law and some registered organizations. This is evident from the fact that they are constantly concerned about the illegitimacy of their actions by their actions. Naturally, all this prevents the sustainable development of not only folk medicine, but also of the national healthcare system.

That is why it is proposed to adopt the Law of the Republic of Uzbekistan "On folk medicine", which provides a systematic basis for the 
interaction of folk medicine participants and ensures its effective development.

\section{Studying the laws of other countries}

Currently, in countries such as China, Japan, Vietnam, Korea, Laos and Malaysia, folk medicine has received official status. For example, in China, healers give about 40 percent of medical services. (No less in Uzbekistan) The International Health Organization (WHO) has adopted several decisions in the last few years of the last century for a thorough study and study of folk medicine. Consequently, folk medicine serves to improve the health of the population for five thousand years.

In 129 of the 194 members of WHO has the legal status of folk medicine. That is, law regulates it. The legislation of countries such as China, Japan, South Korea, Germany and India has a rich experience in this field. Targeted programs on folk medicine have been adopted in these countries. Many research centers operate.

Studying the experience of CIS legislation in this field, it became clear that in some countries was harmonized with the law, and some were harmonized with legal documents this sphere. In particular, on December 9, 2004 the Law "On folk medicine" was adopted in the Republic of Tajikistan. The folk medicine in the Republic of Belarus, Russian Federation and Kazakhstan is regulated by legislation. In these countries, it is planned to introduce project of law "On folk medicine" in parliament this year.

\section{Goals and objectives of the project of the law}

The goal of the project of the law is to promote gradual development of folk medicine in Uzbekistan with modern requirements and to create a system that will regulate the folk medicine and unite the interests of the participants and state.

The objectives of the project of the law are as follows:

determine the forms of the state regulations on folk medicine such as licensing activities in the field of traditional medicine, to define the qualification requirements for healers, the introduction of compulsory insurance of civil liability and monitoring their activities;

to determinate of allowed types of activity of the folk medicine;

to define the rights and obligations of folk medicine organizations (healers) and customers of folk medicine services;

improving the quality of services and defining legal standards for their implementation.

\section{Expected results of adoption of the law:}


Forms and significantly strengthens the legal system that regulates folk medicine;

It will ensure the protection of the legitimate rights and interests of consumers who are provided the healers services. It will eliminated threats of their lives and health;

Establishes control mechanisms for the fulfillment of the obligations undertaken by the folk medicine institutions (healers);

Enhances the quality of services provided by the healers;

Stops access to people who working in the field of folk medicine illegally (pseudo healers);

Increases the effectiveness of management of folk medicine;

Legitimizes tax revenues from folk medicine by legal regulation;

It ensures sustainable development the integrated system of both folk medicine and modern medicine, and optimizes the interaction of all its participants. 


\section{REFERENCES}

1 Constitution of the Republic of Uzbekistan. T: Uzbekistan, 2017, p. 9.

2 V.Tumanov. Commentary on the Convention for the protection of human rights and fundamental freedoms and its Practices. -M .: Norm 2017.

3 Yu.Sergeev. Medical law. Educational complex in 3 volumes. - M., 2008. - p. 784.

4 S.Ibeneme, G.Eni, A.Ezuma, G.Fortwengel. Roads to Health in Developing Countries: Understanding the Intersection of Culture and Healing, Current Therapeutic Research, Volume 86, 2017, pp. -13-18. https://www.sciencedirect.com/science/article/pii/S0011393X17300036

5 "Provisions on professional work and the rights of medical workers." Resolution of the Central Executive Committee of Soviets SNCUzSSR№ 99 dated October 31, 1926.

6 Seifullmulukov I.A. To the question of healerism in Uzbekistan // Medical thought of Uzbekistan. Journal of subtropical, curative and preventive medicine. № 9-10. June July. Tashkent, 1928. -pp. 63-71.

7 Collection of the legislation of the Republic of Uzbekistan, 2006, No. 41, Art. 405. 